\title{
Modified Piston Design for Better Combustion Efficiency
}

\author{
Asok R \\ Assistant Professor: Department of Mechanical \\ Engineering Rajadhani Institute of Engineering and Technology \\ (RIET) Thiruvananthapuram, India
}

\author{
Akhil Vijay \\ Student: Department of Mechanical Engineering \\ Rajadhani Institute of Engineering and Technology \\ (RIET) Thiruvananthapuram, India
}

\section{Ashik V}

Student: Department of Mechanical Engineering Rajadhani Institute of Engineering and Technology (RIET)

Thiruvananthapuram, India

\begin{abstract}
The ultimate goal of every diesel engine is to convert the potential energy of the diesel fuel into mechanical energy that moves the car forward. It has already been explained that the combustion reaction of the diesel fuel is responsible for this is $\left[4 \mathrm{C}_{12} \mathrm{H}_{23}+71 \mathrm{O}_{2} \rightarrow 48 \mathrm{CO}_{2}+46 \mathrm{H}_{2} \mathrm{O}\right]$ but these conditions are not perfectly happening in real life practical condition. Every automobile company is trying to improve its combustion efficiency by reducing pollution. Reduction in pollution means better in terms of fuel efficiency as well. This project discusses the reduction of pollution in a diesel engine by redesigning the piston crown and placing the injector at top of the cylinder. As compared to an ordinary diesel engine, this arrangement helps to improve uniformity inside the cylinder. Hexagon geometry is designed above the piston crown. Diesel engine injector has 6 orifices and each orifice will inject diesel fuel directly to each face of the hexagon. This arrangement helps to increase the flame travel throughout the cylinder. The impact of this arrangement is clearly reflected in the $K$ value and HSU value in the pollution report.
\end{abstract}

Keywords-Combustion, HSU value (Hartridge smoke unit), K_value

\section{I.INTRODUCTION}

Combustion efficiency is a measurement of how good the fuel is utilized by the engine in a better way. This is different from the value on the analyzer, which is reflective of the total amount of heat available from the fuel minus the losses from the gasses going up the stack. Stack loss is the amount of heat carried by dry flue gases and the moisture loss. It is a good indicator of appliance efficiency. The stack temperature is the temperature of the combustion gases leaving the appliance and reflects the energy that did not transfer from the fuel to the heat exchanger. The lower the stack temperature, the overall efficiency of the heat exchanger increases. The combustion efficiency calculation has both the stack temperature and the net heat and moisture losses. This would include losses from dry gas, moisture, and losses from the production of $\mathrm{CO}$. The

\author{
Dr. M. D. Sreekumar \\ HOD: Department of Mechanical Engineering \\ Rajadhani Institute of engineering and technology \\ (RIET) Thiruvananthapuram, India
}

\author{
Anand Krishnan U \\ Student: Department of Mechanical Engineering \\ Rajadhani Institute of Engineering and Technology \\ (RIET) Thiruvananthapuram, India \\ Amal S \\ Student: Department of Mechanical Engineering \\ Rajadhani Institute of Engineering and Technology (RIET) \\ Thiruvananthapuram, India
}

diesel combustion equation is explained as, $4 \mathrm{C} 12 \mathrm{H} 23+71 \mathrm{O} 2$ $\rightarrow 48 \mathrm{CO} 2+46 \mathrm{H}-2 \mathrm{O}$. This is for the complete combustion of diesel, which does not happen in real life practical conditions. Other

Products can include $\mathrm{CO}$ and unburned fuel. When the reaction is not the complete combustion this results in less energy. This happens when there is a lack of oxygen so not all of the fuel can combust and can also be seen in a Bunsen burner. The major drawback of diesel engines is their emission of toxic air pollutants. These engines mainly discharge high levels of particulate matter, $\mathrm{NOx}, \mathrm{CO}$, and odor compared with sparkignition engines. Consequently, in the small-engine category, consumer acceptance is less. Incomplete combustion inside the cylinder is the main reason for all those toxic pollutants. These gases are highly poisonous and toxic for humans, plants and animals. Exhaust treatment devices do oxidation and reduction process to reduce such unwanted pollutants. Our motive is to use the oxygen effectively inside the cylinder and improving uniformity.

\section{EXPERIMENTAL FACILITY}

\section{A. Setup}

The engine used here is a $435 \mathrm{cc}$ single-cylinder, 4 stroke, 2 valve naturally aspirated diesel engine. Which is shown in Fig.1. 


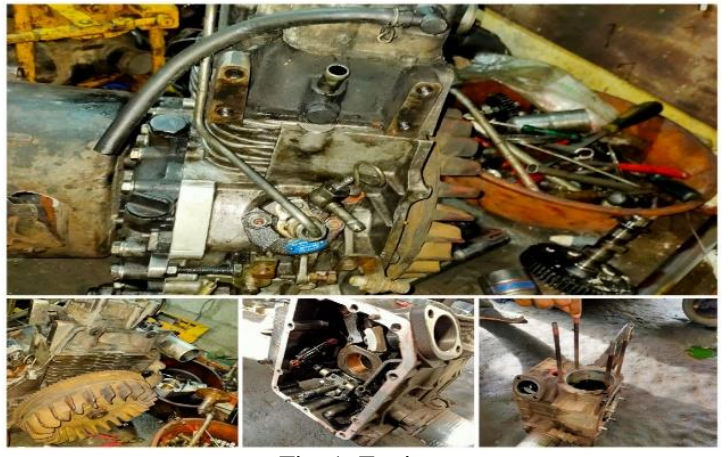

Fig. 1: Engine

Table.1: The technical specification of engine

\begin{tabular}{|c|c|}
\hline Engine capacity & $435 \mathrm{cc}$ \\
\hline No of stroke & 4 \\
\hline No of valve & 2 \\
\hline Type of injection & Direct fuel injection \\
\hline Cooling system & Forced air cooling \\
\hline Bore and stroke & $86 \mathrm{~mm}$ and 75mm \\
\hline Maximum power & $5.75 \mathrm{KW} @ 3400$ RPM \\
\hline Maximum torque & $20 \mathrm{NM} \mathrm{@} \mathrm{2200} \mathrm{RPM}$ \\
\hline Injection pressure & 280 bar \\
\hline No of nozzle holes & 6 \\
\hline Nozzle diameter & $0.1275 \mathrm{~mm}$ \\
\hline Compression ratio & $9: 1$ \\
\hline
\end{tabular}

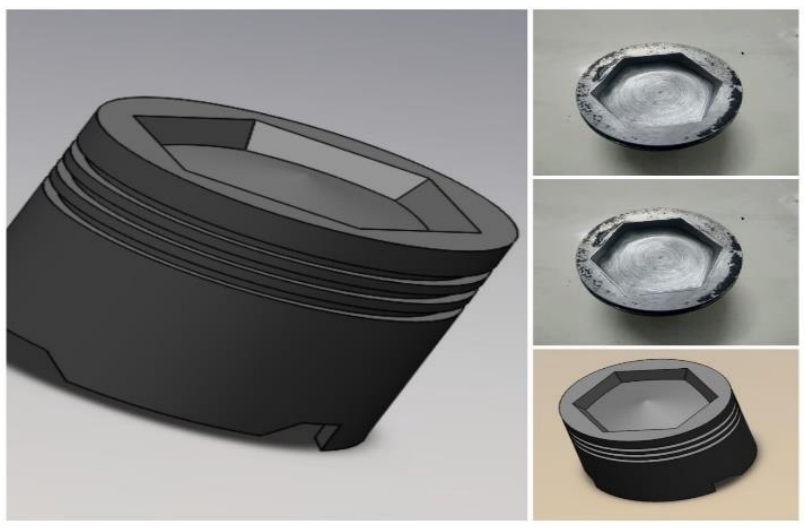

Fig. 2: Design of piston

Table. 2: characteristics of piston

\begin{tabular}{|c|c|}
\hline Diameter of the piston & $86 \mathrm{~mm}$ \\
\hline Thickness of the piston & $15 \mathrm{~mm}$ \\
\hline Depth of the piston & $10 \mathrm{~mm}$ \\
\hline Material & Cast aluminum alloy \\
\hline Length of the piston & $129 \mathrm{~mm}$ \\
\hline
\end{tabular}

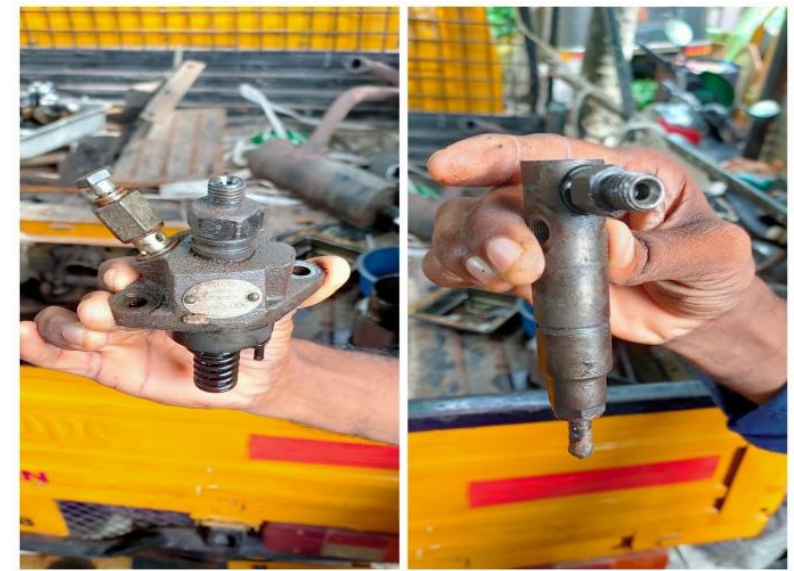

Fig. 4: Diesel pump and injector

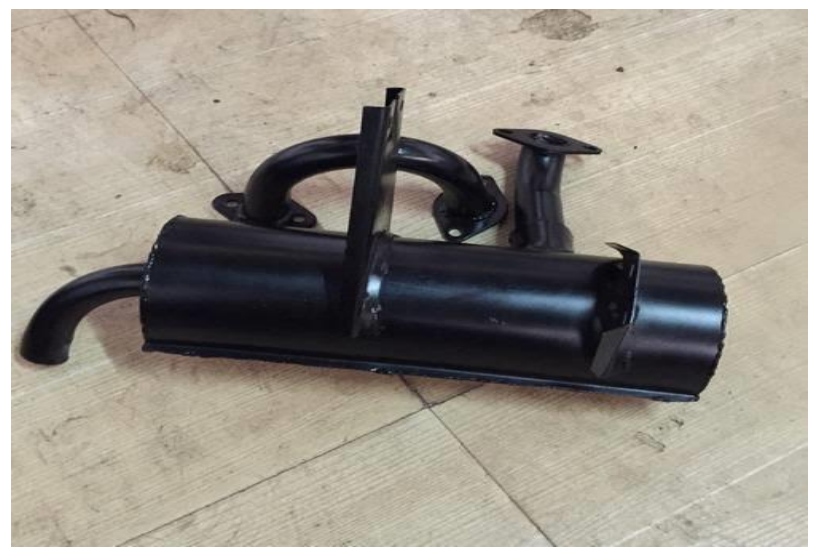

Figure 4 Exhaust pipe

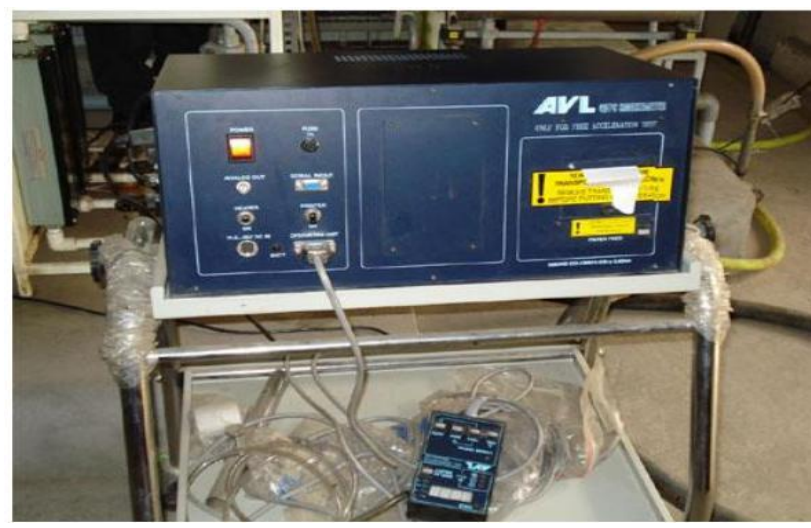

Fig. 5: AVL smoke meter 
Table 3: general parameters of the smoke meter

\begin{tabular}{|l|l|l|}
\hline \multicolumn{2}{|c|}{ General Parameter } \\
\hline Measurement & Opacity degree K value, light absorption coefficient N value \\
\hline & Light absorption coefficient N valle \\
\hline Technology & Partial flow sampling-type \\
\hline Measuring range & K Value & N Value \\
\hline & $0-100 \%$ & $0-16 \mathrm{~m}-1$ \\
\hline Resolution & $0.01 \%$ & $0.10 \%$ \\
\hline Accuracy & $\pm 3 \% \mathrm{FS}$ \\
\hline Warm-up time & 15 minutes \\
\hline Display & LCD display \\
\hline Response time & TD+T90:1 second \\
\hline Power & AC220V $\pm 10 \% 50 \mathrm{~Hz} \pm 1 \mathrm{~Hz}$ \\
\hline Operation temperature & $0 \sim 40^{\circ} \mathrm{C}$ \\
\hline \multirow{2}{*}{ Dimension } & Display:450mm*260mm*180mm(L*W*H) \\
\cline { 2 - 3 } & Opacity meter:460mm*230mm*465mm(L*W*H) \\
\hline Weight & Display:5kg, Opacity meter:7kg \\
\hline \multirow{2}{*}{ Standard accessories } & Sampling pipe, sampling probe and handle, \\
& communication cable, RS-232 cable, power cable \\
\hline Options & Inbuilt printer, RPM measurement \\
\hline
\end{tabular}

\section{B. Experimental procedure}

Experiments were carried out using a $435 \mathrm{cc}$ single-cylinder, 4 strokes, (shown in fig 1) naturally aspirated diesel engine. Exhaust gas pollution testing was carried out using AVL smoke meter. K_value and HSV value are calculated from the smoke meter. Technical specification of the engine are listed in the table (1). The engine is equipped with a fuel injector nozzle with 6 holes which pressurize the fuel and injects at a max pressure of $280 \mathrm{bar}$. The fuel injector is placed centrally over the cylinder head. The engine operates at a constant speed of $1060 \mathrm{rpm}$. The engine is fitted with a hexagonal-shaped piston crown. Diesel fuel is used for the whole procedure. During the testing of the stock piston and modified piston brand, new engine oils were used.

\section{Working principle}

The stock piston of the engine is replaced with a modified piston and the diesel injector is placed at the top of the cylinder. The injector has 6 nozzles and each nozzle inject diesel sprays to each face of the hexagon which improves the natural swirling also the flame travel will increase to the piston head. It is proven that the piston bowl diameter ratio and cylinder bore affect the velocity field. Modified piston shows an improved late, cycle air mixing during diffusion combustion by uniformly tracking the near-wall jet flow back towards the center of the chamber, which increases the level of turbulence[2][3]. This phenomenon helps to improve combustion efficiency and provide faster burnout which reduces the emission of toxic pollutants like NOx, soot, etc. This arrangement helps to reduce the collision of flames each other and helps flames to capture more amount of oxygen. Also, it helps to improve the uniformity inside the cylinder.
Clean and improved combustion is the final result. On each stage of development, the exhaust gas is measuring and calculating its $\mathrm{K}$ value and HSU value.

\section{RESULTS AND DISCUSSIONS}

Table: 4 Pollution test result of ordinary piston

\begin{tabular}{|c|l|l|l|l|}
\hline SL.NO & $\begin{array}{l}\text { IDLE } \\
\text { RPM }\end{array}$ & $\begin{array}{l}\text { MAX } \\
\text { RPM }\end{array}$ & K_VALUE & $\begin{array}{l}\text { HSU } \\
\text { VALUE }\end{array}$ \\
\hline 1 & 1060 & 3120 & 0.4 & 16.90 \\
\hline 2 & 1060 & 3324 & 0.51 & 19.65 \\
\hline 3 & 1060 & 3422 & 0.58 & 22.02 \\
\hline 4 & 1060 & 3465 & 0.71 & 26.35 \\
\hline
\end{tabular}

AVG $\quad 0.56$

Table: 5 Pollution test result of modified piston

\begin{tabular}{|c|l|l|l|l|}
\hline SL NO & $\begin{array}{l}\text { IDLE } \\
\text { RPM }\end{array}$ & $\begin{array}{l}\text { MAX } \\
\text { RPM }\end{array}$ & K_VALUE & $\begin{array}{l}\text { HSU } \\
\text { VALUE }\end{array}$ \\
\hline 1 & 1060 & 3120 & 0.36 & 14.8 \\
\hline 2 & 1060 & 3324 & 0.42 & 17.55 \\
\hline 3 & 1060 & 3422 & 0.48 & 19.76 \\
\hline 4 & 1060 & 3465 & 0.59 & 24.68 \\
\hline
\end{tabular}

AVG $\quad 0.462$

A. GRAPH ANALYSIS BETWEEN RPM AND K_VALUE

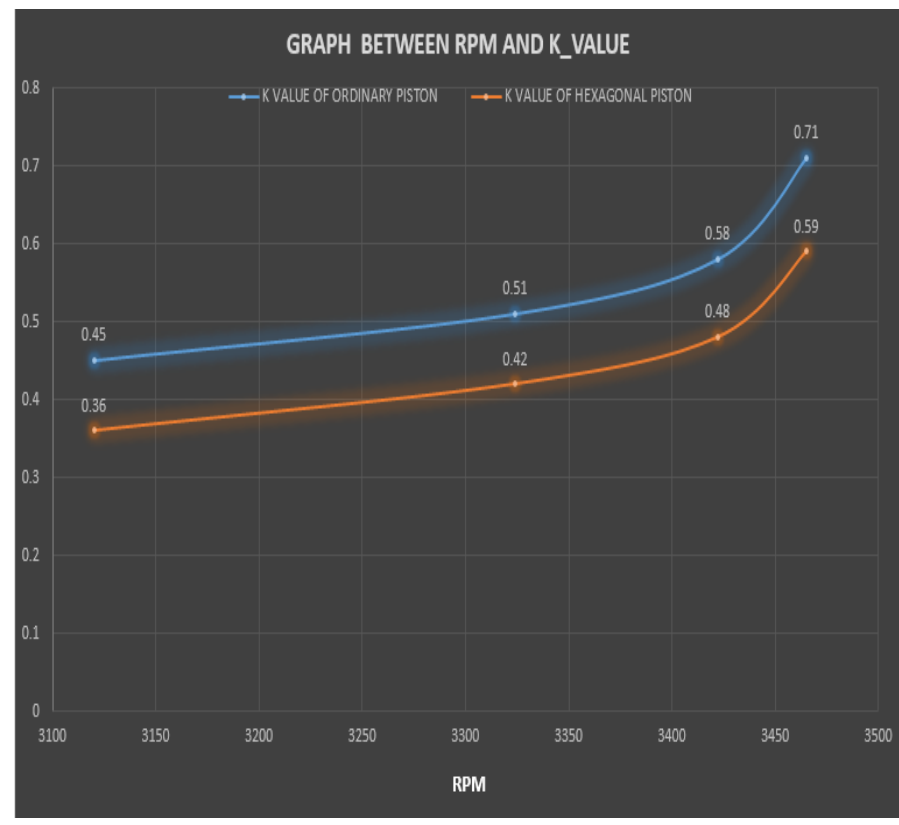


B. GRAPH ANALYSIS BETWEEN RPM AND HSU VALUE

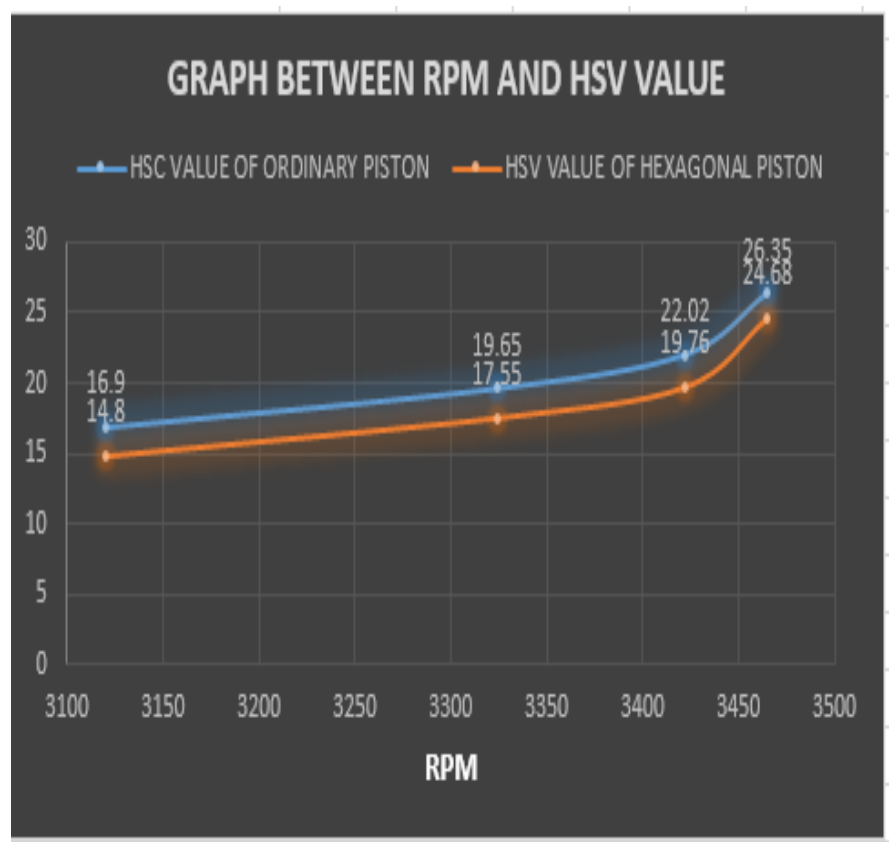

By comparing both pollution reports and graphs which are mentioned above, it is clear that there is a marginal difference in both K_Value and HSU value. Deviation of lines in the graph also expressing that hexagonal piston design produces much better combustion than ordinary piston design. Due to less HSU value in higher rpm smoke density reduced dramatically. This whole project happens on a small capacity single-cylinder diesel engine while considering a higher displacement multiple cylinder engines, then the pollution numbers will be much more expressive. Without any additional huge investment, every diesel automobile manufacturers can use this design for reducing pollution content. This whole arrangement will help to reduce toxic pollutant contents of exhaust gas like Nox, CO, and soot. Better in combustion means better fuel efficiency as well. So simply the whole arrangement helps both our economy as well as our environment.

\section{CONCLUSION}

The main objective of our project was to develop improved combustion in diesel engines by using max oxygen available inside the cylinder. We can effectively make use of the available oxygen and improved the uniformity inside the cylinder using hexagonal piston design by possible resources that we can arrange. We hope that through this project we will be able to contribute a part in effective pollution control and through this, we can save our mother earth and the whole ecosystem. Also through an increase in fuel efficiency, the whole project is supporting the economy too.

\section{REFERENCES}

[1] Combined effects of piston bowl geometry and spray pattern on mixing, combustion and emissions of a diesel engine: A numerical approach Shahanwaz Khana,*, Rajsekhar Panuab, Probir Kumar Bosec aDepartment of Mechanical Engineering, Aliah University, New Town, Kolkata 700156, India bDepartment of Mechanical Engineering, National Institute of Technology, Agartala 799046, India cNSHM Institute of Engineering and Technology, Durgapur 713212, India

[2] Design of piston bowl geometry for better combustion in direct-injection compression ignition enginePRABHAKARA RAO GANJ**, RUDRA NATH SINGH, V R K RAJU and S SRINIVASA RAO Department of Mechanical Engineering, National Institute of Technology, Warangal 506 004, India email: ganjiprabhakar@gmail.com MS received 2 September 2016; revised 17 March 2017; accepted 7 September 2017; published online 7 June 2018

[3] Effects of a wave-shaped piston bowl geometry on the performance of heavy duty Diesel engines fueled with alcohols and biodiesel blendsTankai Zhang ${ }^{\text {a, * }}$, Jan Eismark ${ }^{\text {a, }}{ }^{\text {, }}$, Karin Munch ${ }^{\mathrm{a}}$, Ingemar Denbratt

[4] Effect of Inlet Slot Number on the Spray Cone Angle and Discharge Coefficient of Swirl Atomizer Mohd Syazwan Firdaus Mat Rashid*, Ahmad Hussein Abdul Hamid, Ow Chee Sheng, Zulkifli Abdul Ghaffar Faculty of Mechanical Engineering, Universiti Teknologi MARA (UiTM), 40450 Shah Alam, Selangor, Malaysia

[5] K. Hart, M. Azevedo, J. Rebello, C. Ribiero, Piston without sleeves for the piston pin, Pat. 6557457 USA, MPKF16 J 1/04, FederalMogul World Wide Inc., № 09/688677, stated.. 16.10.2000, publ. 06.05.2003, NPK 92/223.

[6] Thermal Protection of Internal Combustion Engines Pistons N.Yu. Dudarevaa, ${ }^{*}$, R.D. Enikeeva, V.Yu. Ivanovb aUfa State Aviation Technical University, 12, Karl Marx St., Ufa 450008, The Russian Federation bPublic Joint Stock Company Ufa Engine Industrial Association, 2, Ferin St., Ufa 450039, The Russian Federation

[7] The Study on the Effect of the Piston Shapes through Biodiesel Mixture Combustion in Diesel Engine Changchun Xu1, Md. Abul Kalam2, HaengMuk Cho3,* 1.3Division of Mechanical and Automotive Engineering, Kongju National University 1223-24, Cheonan Daero, Seobuk-gu, Cheonan-si, Chungcheongnam-do 331-717, South Korea. 2Department of Mechanical Engineering, University of Malaya

[8] V.N. Nikishin, Formation and providing indicators of quality of automobile diesels at a stage of their design and operational development: Doctor of Engineering thesis, Naberezhnye Chelny, 2006, 377 p.

[9] Yu.N. Nikitin, S.V. Koroteyev, P.S. Makarevich, Profile of the piston and lubrication of the parts of cylinder-piston group, automotive industry. 10 (1990) 13-14. 